\title{
FEDERAL AND REGIONAL REGULATION OF INNOVATION ACTIVITIES IN RUSSIA
}

\author{
Andrey Petrovich Garnov ${ }^{1}$ \\ Natalia Alekseevna Prodanova ${ }^{2}$ \\ Victoria Yuryevna Garnova ${ }^{3}$ \\ Larisa Vladimirovna Shabaltina ${ }^{4}$ \\ Elena Ivanovna Zatsarinnaya ${ }^{5}$
}

\begin{abstract}
In the modern world of integration and globalization of world markets, the importance of innovation in the economy and development in the general system of government at the federal and regional levels has increased significantly. The complexity of the tasks being solved requires the development of a modern theoretical and methodological basis for regional management, the formation of adapted organizational and economic, financial and budgetary and other forms and tools for managing innovation and investment attractiveness. The main goal of the study is to reveal the peculiarities of the

functioning of regional innovation
\end{abstract} systems, describe the indicators and features that determine the specifics of each regional innovation system, consider the main methodological approaches to the formation and functioning of regional innovation systems, disclose the essence and possibility of applying general theoretical principles and indicators of state statistical reporting to analyze the innovative position of regions.

Keywords: public administration, region, innovation, goal, criterion, principle, indicator, result, position, potential, activity

1 Plekhanov Russian University of Economics, Russian Federation, email: info@ores.su, https://orcid.org/0000-0002-4093-4604

2 Plekhanov Russian University of Economics, Russian Federation, email: prodanova00@mail.ru, https://orcid.org/0000-0003-1496-1470

3 Plekhanov Russian University of Economics, Russian Federation, email: russia@prescopus.com, https://orcid.org/0000-0001-9967-7254

${ }^{4}$ Plekhanov Russian University of Economics, Russian Federation, email: editor@ores.su, https://orcid.org/0000-0002-3006-6081

${ }^{5}$ Plekhanov Russian University of Economics, Russian Federation, email: global@ores.su, https://orcid.org/0000-0003-0166-846X 


\section{INTRODUCTION}

Information and economic problems of interaction between economic entities participating in innovative implementation are carried out within the boundaries of the regional innovation system (RIS), which is a separate element of a single national innovation task. Accordingly, the innovation system at the regional level should be studied as a macro-system of the general - the national system. However, the regional innovation system consists of three micro-systems - market, municipal and state (Dudin et al., 2019; Gapsalamov et al., 2020).

Each of these three subsystems at the local level of management includes state and municipal, as well as private (market) commercial and noncommercial economic entities. Regional innovation systems make a specific contribution to the level of development of the entire national (Federal) innovation system. However, each regional innovation system has specific characteristics, expressed by such indicators as the level of development, the volume and quality of resource potentials, the degree of influence on socio-economic processes and their trends in the region.
In our opinion, the regional innovation system should have the following features: the degree of integration into the overall national innovation system of the country; the degree of compliance with national development priorities, the degree of consistency with the national (Federal) regulatory framework; the presence of common basic methodological approaches and theoretical principles on the formation of national and regional innovation systems and institutions of innovative development; the degree of rationality of using the advantages of the region's competitive position (key success factors) for further innovative development (Yemelyanov et al., 2019); the degree of equal participation of all stakeholders - regional and municipal government bodies and economic entities in the development of innovative processes in the region; the degree of compliance of internal strategic goals and criteria for implementing these goals in economic entities with the overall national and regional strategic goals and programs for innovative development of the territory; the degree of compliance of regional innovation programs with the priorities of territorial development and achieving a higher socio-economic level 
and quality of life of the population. These features allow, on the one hand, to create a unified innovation space on the territory of Russia, and, on the other hand, to create an internal socially and economically oriented innovation policy and plans for its implementation.

\section{LITERATURE REVIEW}

Problems and features, as well as theoretical foundations, including methodological approaches and principles of regional innovation policy formation, are studied not only by foreign, but also by domestic researchers (Oseevsky, 2011).

It should be noted that the formation of national and regional innovation systems are based on the same methodological approaches, which include system, complex, normative, process, program-target, situational, and qualimetric. These approaches define the General principles of building systems, such as consistency, complexity, normativity, continuity, program-target orientation, adaptability and quantitative measurability of indicators - criteria for achieving the goals of innovation policy and the results of implementing plans and specific activities (Sharafutdinov et al., 2019; Paptsov et al, 2019). However, in addition to the General theoretical principles inherent in all regional systems, there are special ones that adequately reflect regional problems and features of socio-economic and innovative development of each particular region, and create prerequisites for more rational and effective management of innovation processes in the region (Kheyfets and Chernova, 2019; Klimontowicz, 2019). It should be noted that the tasks of forming regional innovation systems were carried out in certain territories before the state national innovation system was created at the Federal level of management. Such systems operated in regions such as Saint Petersburg and the Republic of Tatarstan. Special theoretical principles for regional innovation systems include proportionality and balance of all processes on the territory of the region: political, legal, economic, sociodemographic, scientific and technical. They include innovative, cultural, environmental; interconnectedness of innovative and socio-economic processes occurring in the region with similar ones in neighboring regions that are part of the megaregion-the Federal 
district; availability of all types of resources for innovation both quantitatively and qualitatively; dependence on the availability of economic and innovative growth points in the region; productivity of various types of applied research and development; effectiveness of innovation in various types of applied research and development; relevance and timeliness of patent applications; reliability of the results of applied research and development in the form of advanced production technologies in the practical activities of economic entitiesstate, municipal and private, both commercial and non-commercial; the activity of innovative activities of economic entities. Specific principles of each region in innovation activities include: proportionality of expenditures on basic research, applied research and development; proportionality of training of candidates and doctors of science; productivity of the processes of training candidates and doctors of science; efficiency of the processes of training candidates and doctors of science; cost effectiveness of technological innovations; proportionality of exports and imports of innovative products in the commodity structure of foreign trade in the region.

\section{MATERIALS AND METHODS}

The main research tools used in this work are system analysis. Methods of empirical research, principles of formal logic, synthesis and analysis of the works of Russian and foreign scientists are used to study theoretical and practical material.

\section{RESULTS}

The main differences between regional innovation systems based on the fact that regional innovation processes are characterized by a high degree of differentiation according to the following criteria: a demographic condition that affects the degree of security researchers and human resources appropriate qualifications; the status and degree of wear of fixed assets; accessibility, influence the provision of all types of missing resources from other regions; the degree of differences in economic and scientific specialization of regions; the degree of saturation of all types of own regional resources.

Thus, the principle of consistency allows us to consider the region as a separate territory that 
implements internal political and legal, economic, demographic, cultural, scientific and technical, environmental and environmental processes, as well as the development and implementation of innovation policy in a changing external environment, which includes similar processes and innovation policies of other regions and the Federal state innovation policy.

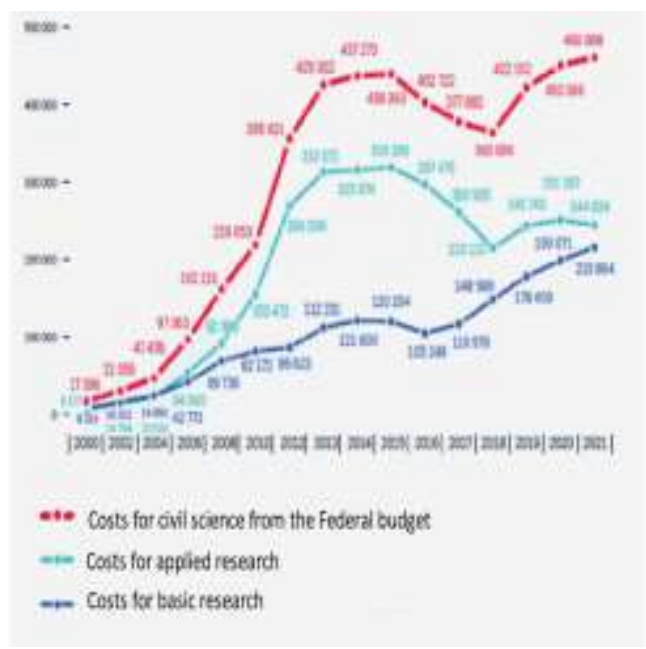

Fig. 1. Allocations for civil science from the Federal budget in 2000-2021 in millions of rubles

The total amount of federal budget allocations for civil science in 2019 in accordance with Federal law No. 459-FL26 will amount to 422.15 billion rubles, or $2.65 \%$ of Federal budget expenditures. The cost of basic research will be 178,4 billion rubles, or 1.1 percent of Federal spending, and spending on applied research will be 243,7 billion rubles, or $1.5 \%$ of Federal budget spending. Since 2014, spending on basic research has been growing at a faster rate than spending on applied research.

It is planned to allocate more than 450 billion rubles annually to civil science, which will lead to an increase in the share of allocations for civil science in Federal budget expenditures to $2.89 \%$ in 2020-2021.

The principle of complexity reflects needed to be considered strategic directions of innovation as a set of regional target programs in various 
spheres and sectors of the economy, aimed at implementing a single goal is to increase the volume of production of the gross regional product in General and per capita on the basis of increasing the productivity of public labor. The main factor of productivity growth of this labor is the degree of innovative development of the region.

The normativity principle should be used to define criteria for achieving long-term strategic goals that are normative (intuitive) forecasts and reflect the desired results of regional innovation activities. Moreover, it should be noted that normative forecasts can be guided by the quantitative results of innovation activity already achieved in other regions - the best, average, and nearest in size.

The principle of continuity implies the creation of a continuous process of analyzing current innovation activities and adjusting the goals and criteria for their achievement. This adjustment of old goals and criteria and the formation of new ones should be carried out annually after the implementation of specific measures and evaluation of their results, identifying the degree of deviation of actual results from the planned ones.
The principle of program-target orientation assumes the formation of a multi-level model of target orientation of the management system of state, municipal and private innovation processes in the region. Each regional model should become a fragment of the overall national model of innovation activity in Russia, contain strategic goals, plans and specific activities, and be focused on the implementation of the state innovation policy developed at the Federal level of management.

The principle of adaptability serves as the basis for creating processes for monitoring and forecasting the dynamics of changes in environmental factors at the Federal, mega-regional and regional levels of government, which have the strongest impact on innovation activities in the studied region. Such factors are exogenous unmanageable or controlled variables, the state and rate of increase or decrease, which must be anticipated in advance, and depending on the expected changes, adjust the old goals and plans of innovation or form new ones.

The principle of quantitative measurability of criteria for achieving strategic goals and current results of implementation of specific activities 
allows us to consistently perform the functions of accounting, control and regulation of innovation processes in the region by the appropriate management system. The accounting function is designed to determine the quantitative States of current innovation processes. The control function allows you to detect deviations in the actual quantitative results of the implementation of plans and specific activities from the planned ones and become a process of forcing and bringing the objects of innovation into a pre-planned state. And the regulation function allows you to develop and maintain the proportionality principle, which is related to the particular principles of creating an innovative environment in a particular region, through the use of portion control.

The scientific literature has developed a classification of regions based on such features as: the degree of innovative development; innovative potential; innovative activity (Nikishina, 2010). In our opinion, this division is necessary for assessing the state of innovation activity in the regions and forming appropriate policies for further innovative development.
However, each of these three indicators should be quantified based on the indicators of state statistical reporting of the Russian Federation and trends in these indicators (Regions of Russia) should be identified. (Socio-economic indicators, 2017).

In order to develop the scientific infrastructure, scientific organizations, in accordance with paragraph 4.1 of article 5 of Federal law No. 127-FL, create centers for the collective use of scientific equipment, unique scientific installations (USI). According to the website "Scientific and technological infrastructure of the Russian Federation" www.ckp.rf.ru, 301 CCPS are registered, 359 USIs are registered, and eight megasayence-class installations are being created.

The efficiency of the created CCP and UNU is on average about $80 \%$, which is insufficient for the significant amounts of Federal budget funds spent on their creation.

At the same time, expenditures under the Federal project "Development of advanced infrastructure for research and development in the Russian Federation" of the national project "Science" (hereinafter - project S-2) have the largest share in the structure of 
expenditures for the development of scientific infrastructure: $57.1 \%$ of the budget allocations for the SBR and $50.0 \%$ of the cash execution as of December 1, 2019.

The S-2 project solves the tasks of creating an advanced infrastructure for research and development, innovation, including the creation and development of a network of unique scientific installations of the megasiens class, as well as updating at least $50 \%$ of the instrument base, set by decree No. 204.

In 2019, 4.3 billion rubles were allocated from the Federal budget to update the instrument base of leading organizations that perform research and development. Execution as of December 1, 2019 amounted to 4.3 billion rubles, or $100 \%$, which indicates the demand for such support.

One of the tools to support the development of scientific infrastructure is also the Federal Targeted Investment Program (hereinafter - FTIP). In 2019, the FTIP includes activities under sections 0110 "Basic research" and 0112 "Applied research in the field of national issues", with a total budget investment of 11.6 billion rubles.

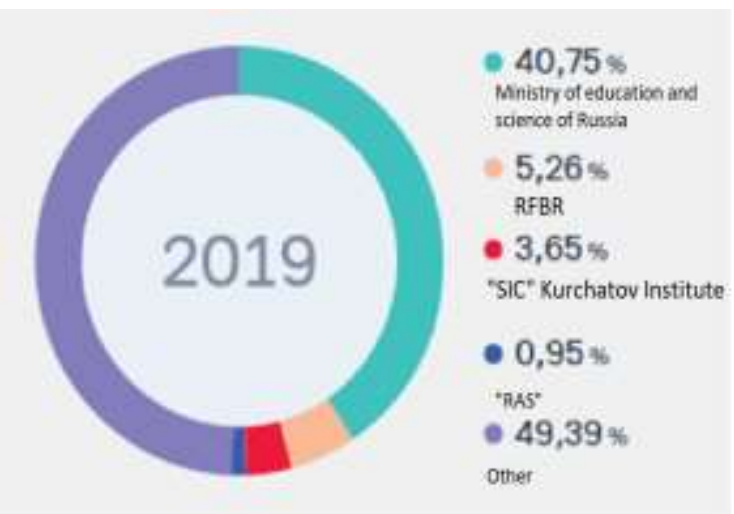

Fig. 2. Structure of allocations for civil science from the Federal budget by chief managers of budget funds in 2019

In 2019 the greatest volume of allocations for civil science from the Federal budget falls on the Russian Ministry of education 172,0 billion roubles, or $41.8 \%$. RFBR dedicated to 22.2 billion rubles $(5.4 \%$ more than in 2018 ), or $5.3 \%$ of total allocations for civil science from the Federal budget, 
NRC "Kurchatov Institute" - 18.6 billion rubles, or $3.7 \%$, ran -4.1 billion, or 0.95 $\%$.

In order to fulfill the task of developing advanced infrastructure for research and development within the framework of the national project "Science" from 2020, it is planned to implement the capital construction project "Construction of two new modern research vessels of unlimited navigation area" of P. P. Shirshov Institute of Oceanology of the Russian Academy of Sciences "with a budget allocation of 4.4 billion rubles for 2020 , 2.3 billion rubles for $2021,1.9$ billion rubles for 2022.

It is planned to build two multifunctional research vessels (hereinafter referred to as MRV) in order to implement the provisions of the Maritime doctrine of the Russian Federation for the period up to 2030 , approved by the President of the Russian Federation. The estimated (maximum) cost of construction of two MRV in 2019 prices is 23.3 billion rubles, and also calculated in the prices of the corresponding years -27.6 billion rubles (including for equipping with modern scientific equipment).

\section{CONCLUSION}

So, in our opinion, the degree of innovative development and innovative potential can be measured using these three types of specific indicators of innovation activity, calculated: per 1000 people of the territory's population; per 1000 people employed in the economy; per 1000 people employed in research and development. For example, the degree of innovative development can be determined by such specific indicators as: internal expenditures on research and development; current expenditures on research and development by type of work (basic research, applied research, development); patent applications filed; patents issued; number of advanced production technologies created; number of advanced production technologies used; costs of technological innovations; volume of innovative goods, works, services.

Innovation activity in the region is defined as a percentage of such an indicator of state statistical reporting as the innovation activity of organizations and is calculated as the ratio of the number of organizations that carried out technological, organizational or marketing innovations to the total number of organizations surveyed for a 
certain period in the region. In our opinion, the most difficult indicator is the innovation potential, which can be calculated as the difference between the existing degree of innovative development of the region and the desired degree in different perspectives long, medium or short-term. These desired forecasted indicators can be the quantitative values achieved on average for the regions of the Russian Federation, on average for the regions of the Federal district-megaregion, the maximum values achieved in any region of the Russian Federation or in the region of the Federal district to which the region belongs; the achieved values in the region with which there are minimal deviations or, as is customary in strategic management, the minimum gap.

The Ministry of economic development of the Russian Federation and the Russian Academy of Sciences have developed a typology for dividing regions into three groups: highly developed (reference) regions with established innovation potential; developing (emerging) innovative regions where innovation potential is one of the main factors of socio-economic development of the territory; underdeveloped regions that do not have their own specialists, attract staff and use the experience of other regions. This typology corresponds to the international one, which also distinguishes three types of regions: knowledge hubs; industrial zones; regions with a low level of research and development development (Okrepilova, 2010).

In our opinion, the main feature of this division of regions is not the innovation potential as such, but the innovation base that the regions have. Such a base can include specific indicators that characterize the degree of innovative development of the region, and if you conduct a comparative analysis of the innovation base of regions in one or more Federal districts or all regions of Russia using the ranking method, you can identify the regions that make up these three groups according to the additive rank of the innovation position of the studied regions.

The main motivational tools applied to personnel and enterprises and organizations in the real sector of the economy are financial instruments grants and subsidies from the Federal budget. In 2019, the Federal budget provides 11.48 billion rubles for measures to develop human resources, or $2.7 \%$ of the total amount of funds 
allocated for the development of science.

This is not enough to achieve the goal of achieving breakthrough scientific, technological and socio-economic development of the Russian Federation.

At the same time, the national project "Science" and state program No. 47 do not provide for comprehensive social support for graduate students, young scientists and researchers, as well as measures to attract highly qualified researchers.

Russia is lagging behind in a number of financial indicators and qualitative characteristics of science from the level of developed countries. Russia ranks tenth in the ranking of the world's leading countries in terms of domestic research and development expenditures based on purchasing power parity of national currencies. By the share of science expenditures in GDP $(1.1 \%)$ Russia is significantly behind the leading countries of the world, being in 34th place. Even lower is the position on the indicator of internal research and development costs per researcher (in the equivalent of full employment) -47 th place (93 thousand dollars of the USA).

\section{REFERENCES}

Nikishina E. S. Development of strategic directions of innovative development of regions / E. S. Nikishina, N. M. Filimonova // Problems of modern economy- 2010. - № 3 (35). - Pp. 295298.

Oseevsky M. E. Features of the economy of the post-crisis period and the implementation of innovative ways of development in St. Petersburg / M. E. Oseevsky // Economy. Taxes. Pravo. 2011. - No. 1. - P. 60-64.

Regions Of Russia. Socio-economic indicators. 2017: Stat. sat. / Rosstat. - M., 2018.

Fundamental problems of spatial development of the macroregion in the transition to an innovative economy / ed. - SPb. Nauka, 2010, 595 p.

Babkina L. N., ChubinskayaNadezhdina S. V. Features of regional innovation systems functioning// Foresight "Russia": the future of technology, economy and man. Volume 2 / Collection of reports of the V St. Petersburg international economic Congress (spec-2019) / Under the General editorship of D. S. Bodrunova. Saint Petersburg: INIR, 2019.

Report on the results of the expertanalytical event " Identification of the main reasons that hinder scientific 
development in the Russian Federation: assessment of the scientific infrastructure, the sufficiency of motivational measures, ensuring the attractiveness of the work of leading scientists." Accounting chamber of the Russian Federation, 2020. [Electronic resource] - access Mode: http://fgosvo.ru/uploadfiles/Work_mate rials_disscusion/sp.pdf

Akoff R. Planning the future of the Corporation / R. Akoff [Electronic resource]: Analytical portal "Humanitarian technologies". - Mode of access:

http://gtmarket.ru/files/book/Russell_Ac koff

Creating_the_Corporate_Future.pdf.

Galbraith J. K. New industrial society / J.

K. Galbraith [Electronic resource]: Analytical portal "Humanitarian technologies". - Mode of access: http://gtmarket.ru/laboratory/basis/ 5021.

Leontiev V. V. General Economic problems of intersectoral analysis / V. V. Leontiev [Electronic resource]: LiveLibsocial network for book readers. - access Mode:

https://www.livelib.ru/author/156290/to p-vasilij-leontev.
Sharafutdinov, R., Gerasimov, V., Akhmetshin, E., Karasik, E., \& Kalimullina, O. (2019). Inclusive development index in Russia: analysis, methods, possibility of application. Revista Genero \& Direito, 8(4), Special Issue, 231-241.

Dudin, M. N., Frolova, E. E., Protopopova, O. V., Mamedov, A. A., \& Odintsov, S. V. (2019). Study of innovative technologies in the energy industry: Nontraditional and renewable energy sources. Entrepreneurship and Sustainability Issues, 6(4), 1704-1713. doi:10.9770/jesi.2019.6.4(11)

Kheyfets, B. A., \& Chernova, V. Y. (2019). Sustainable agriculture in russia: Research on the dynamics of innovation activity and labor productivity. Entrepreneurship and Sustainability Issues, $\quad 7(2), \quad$ 814-824. doi:10.9770/jesi.2019.7.2(2)

Klimontowicz, M. (2019). The role of banks' innovativeness in building sustainable efficiency: The case of poland. Entrepreneurship and Sustainability Issues, 7(1), 525-539. doi:10.9770/jesi.2019.7.1(37)

Gapsalamov, A. R., Merzon, E. E., Kuznetsov, M. S., Vasilev, V. L., \& Bochkareva, T. N. (2020). The education system in the context of socio-economic 
transformations. [O sistema educacional no contexto das transformações socioeconômicas] Periodico Tche Quimica, 17(34), 874-883.

Paptsov, A., Nechaev, V., \& Mikhailushkin, P. (2019). Towards to a single innovation space in the agrarian sector of the member states of the eurasian economic union: A case study. Entrepreneurship and Sustainability Issues, $\quad 7(1), \quad$ 637-648. doi:10.9770/jesi.2019.7.1(45)

Yemelyanov, V. A., Yemelyanova, N. Y., Morozova, O. A., \& Nedelkin, A. A. (2018). Specialized computer system to diagnose critical lined equipment. Paper presented at the Journal of Physics:

Conference Series, 1015(5)

doi:10.1088/1742-6596/1015/5/052032 